\title{
Te kaieke tohora \& pai/kea, a encantadora menina das baleias
}

\section{IZABEL Brandäo}

Prolessora associada doutora em Literatura Inglesa

pela Universidade de Sheffield Inglaterra, com atuaçāo no ensino e pesquisa das literaturas de língua inglesa e brasileira da Faculdade de Letras (gracuaçăo e pos-graduaçao) da Universidade Federal de Alagoas (UFAL), É coordenadora do Grupo Mare\&sal Estudos e Pesquisas Interdisciplinares. É também pesquisadora do CNPq.

Resumo: Este ensaio analisa o filme A encantadora de baleias, da diretora neozelandeza Niki Caro. cujo roteiro foi baseado no romance Whale Rider, do tambern neozelandéswiti lhimaera através de uma leitura critica leninista dos milos. No filme. a jornada co heró é representada através da heroína Paikea, uma adolescente cuja busca de identidade trava um confronto com a tradiçāo cuitura' maori, que é patriarcal e terrenhamente defendida pelo awō, o guardiāo das tradiçōes, e contestada pela neta com o aval da avó. As transgressoes trazidas pelo filme mostram a possibilidade de renovaçào de uma tradiçäo sem que se percam os walores ancestrais que demarcam papés sociais e de gènero, lắo fortemente enraizados naquela cuitura.

Palavras chave: Crítica feninista; Cinema neozelandès; “A Encantadora de baleias": Jornada da heróna; Mito e cullura
Abstract This essay anahyses the ffim Whale Fider, directed by New Zealandian director Niki Caro, whose screenplay was based on the novel Whale Fider, by Writ Inimaera, also from New Zealand. The analysis slems from a feminist perception of aty ths in which the hero joumey is represented in the fifin through the heroine Paikea, an adolescent whose search tor an identty confronts the patriarchal Maori cultural tadition, terociously defended by the grandtather, the tradition keeper, as well as opposed by the grand-daughter who has the grandmother's support. The transgression represented in the fim shows the possibility of renewing a tradition without losing ancestrai values that discriminate social and gender roles, so strongly demarcaled in that cillural environment

Keywords: Feminist Criticism; Cinema from New Zealand: "Whale Fider": The Heroine's Journey; wyth and Culture 

"A vida é uma viagem de Hawaiki para Hawaiki, a terra espiritual dos Maori" (site neozelandès)'

"Nāo sou profeta, mas sei que meu povo seguirá em frente" (Whale Rider).

"Quando a própria vida histórica nāo consegue fazer sentido em termos culturais em construçós que anteriormente davam certo, os dramas e narrativas culnurais podem ter a tarefa da poesia, ou seja, a de refazer o sentido cultural, mesmo quando parecem estar desmantelando antigos edificios de significado" (Victor Turner).

\section{De Hawaiki para Hawaiki: a jornada de Paikea}

Whale Rider ou Te Kaieke Tohora, na língua dos povos Maori, que vivem em Aotearoa (Nova Zelândia), é o premiadíssimo filme da diretora neozelandesa Niki Caro, lançado em 2002.2 O roteiro foi baseado no romance do mesmo nome, de 1987, do escritor Witi lhimaera, também neozelandês.

O título brasileiro do filme - A Encantadora de Baleias - é mais poético do que propriamente adequado para o significado que Whale Rider carrega na sua dimensão mitica. A palavra "Rider" quer dizer aquele/a que cavalga. Isso tem urna implicação direta com o mito de Paikea, o herói Maori, que veio de Hawaiki montado numa baleia para a terra Aotearoa.

A jornada de Paikea é arquetípica e, por isso, tem valor colctivo e universal para os povos Maori, especialmente da comunidade Whangara, de quem ofilme traca. Paikea é o herói c é também a própria baleia. Essa jornada é repetida anualmente pelas baleias que migram para a Nova Z.clândia, a fim de procriar e alimentar seus filhotes. Muitas encalham, mas os Maori não consideram isso algo ruim, de causar má sorte. Pelo contrário, as baleias encalhadas, que não conseguem retornar ao mar $e$ morrem na praia, podem servir de alimento para os povos da regiào. 
${ }^{3}$ Disponivel em $<$ http:/maaori.com/ people/maoriara.hems> Acesso em 18 de março de 2005.

+ Cf. final deste trabalho para as referèncias completas.
Otrajeto, conformea lenda (ou mito, se preferirem), tem mais de 15 mil anos. Os Maori descendem de povos que vieram da China, passando por Taiwan, Filipinas, Indonésia, Melanésia, Fiji, depois Samoa, Marquesa, para, há aproximadamente 1.700 anos, mudarem de curso para o Sudeste, para o Taiti, depois para as ilhas Cook, e finalmente chegar à terra de Aotearoa, ou Nova Zelândia, como a conhecemos.

Assim, os povos Maori viersin de Hawaiki, uma terra lendária para onde retornarāo ao morrer:

Nossas histórias tribais nos contam que ao morrerem nossos cotpos, nossos espíritos continuam a viver e recornam para Hawaiki... Assim, a vida ć uma viagem de Hawaiki para Hawaiki, a terra espiritual dos Maori. ${ }^{3}$

Há um dado no minimo curioso a respeito do mito de Paikea e a sua relação com a literatura, que trata especialmente de mitologia, antropologia, bem como de psicologia. Na breve pesquisa que empreendi para tornar meus comentários possíveis, fiz uso de Joseph Campbell, Robert Graves, Erich Neumann, James Fraser e de uma antologia feminista sobre mitologia organizada por Carolyne Larrington. Esses autores não escreveram uma única linha sobre o mito de Paikea, que parece fundamental para a cultura Maori. Por isso, fui buscar outras informações em sites da Internet que falavam do filme e também dos mitos e lendas Maori.

Esse silêncio em torno do mito de Paikea deixa uma imensa lacuna para o estudo dos povos Maori. Campbell. por exemplo, em seu The Hero with a Thousand Faces (1988), que narra a jornada do herói em mitologias ao redor do mundo, apenas trata da baleia enquanto símbolo, sem relacioná-lo a nenhum mito da Oceania. A baleia é uma imagem universal do útero. $\mathrm{E}$ aqui as histórias sào muitas. Uma das mais conhecidas é a jornada bíblica de Jonas, que renasce após ter passado um periodo dentro de uma baleia. Outra história interessante vem dos esquimós: 
fala de um corvo que entra na baleia e lá encontra Nui, a alma da baleia. $O$ corvo termina por matar a baleia, cujo corpo vai parar numa praia onde é descoberto pelo povo, que the corta a carne em pedaços. Esta parece ser a única ligação que se pode tentar fazer com os povos Maori, não por Paikea, mas pelas baleias que encalham e morrem na praia e, entāo, suas carnes podem servir de alimento, conforme já foi mencionado.

E. Neumann (1963), em The Great Mother, refere-se à língua estirada dos povos oceânicos (os Maori integram esses povos) como sinal de poder e de energia dinâmica; refere-se também à baleia no capítulo 10, que é sobre o caráter elementar negativo do Feminino, como

ventre-vaso, tanto como mulher quanto como terra. O trajeto noturno dos corpos celestes pelo mundo inferior é, assim, determinado pelo vaso do destino. O Feminino é o ventre da "baleiadragão", a qual - tal como na história de Jonas - engole o herói solar toda noite no Ocidente: é o destruidor do entardecer (p. 145, ed. brasileira).

Neumann fala também no Feminino Terrivel como ocidente: ele é noite, abismo, mar, profundezas aquáticas, serpente, dragâo, baleia...:

A água tragadora, o útero-terra destruídos, o abismo da morte, a serpente hostil da noite e da morte, a baleia, o mar e a baleia no mar sāo todos aspectos do inconsciente negativo que vive no interior da terra como "água das profundezas"; sob o mundo dos homens, na escuridāo da roite e que representa o perigo das águas torrenciais que ameaçam inundar o mundo (p. 165).

Já James Fraser refere-se ao poder dos chefes Maori: podiam destruir qualquer pessoa caso se sentissem ameaçados, até mesmo se uma pessoa fizesse algo como comer o resto de sua comida, ou coisa semelhante. Fraser 
;O livro A naziáo do filma, do estudiuso americano de cinema Roberto Burgoyne, trata do cinema histórico contemporáneo nos Estados Unidos, mas a sua discussāo do papel do cinema contemporâneo sèrve aos propósitos da discussāo que pretendi empreender a respeito do filme Whale Ridcr c sua releitura do milo de fundação da cultura Maori.

- Em algurs dos artigos publicados na imprensa internacional quando o filrne foi lançado, hí referencias a um outro filme que também tratava da história neozelandesa, só que os comentários acercil desse filme mostram, para a atriz Keisha Castle-Hughes, una percepçāo negativa do seu povo: enquanto Whale Rider far. um percurso de recuperação da auto estima desse povo: Whale Rider mostra um nove significado e sobre o que somos", conforine dir a Lorena Muñor. no "A Girl Shall l.ead Them", artigo de Times. (m) $6 / 5 / 2003$. escreve também sobre o sentido do nomear naquela cultura: caso o chefe de determinada tribo tivesse um nome como "Wai" (água), por exemplo, aquele povo nào poderia mais usar a palavra "wai" no seu sentido anterior de água. Com isso, significados variados foram criados para determinadas palavras, o que levou ao enriquecimento do vocabulário Maori. A palavra "wai" só poderia voltar a ser utilizada quando o chefe "Wai" viesse a morrer. Margaret Orbell (1992), an escrever sobre a mitologia Maori, também nạo se refere a Paikea nem à importância da baleia para essa cultura, mas fornece dados preciosos sobre a presença da mulher, de que falarei mais adiante.

\section{Da narrativa mitica à narrativa fílmica: Paikea - do herói patriarcal à heroína marginal}

Falar deste filme é, sem dúvida, correr o risco de ser óbvia, no sentido das interpretaçōes que podem ser feitas. O filme fala por si, afinal uma das caracrerísticas mais fortes do cinema é exatamente esta: imagens podem falar mais do que mil palavras. E nāo é diferente com Whale Rider, um filme que scrve à lógica própria do cinema contemporâneo que, segundo Roberto Burgoyne (2002, p. 12), utilizando-se do sociólogo Rancière, pode servir de "fomento de uma noção de identidade nacional", pois leva à criação de uma "imagem da sociedade imediatamente legivel para todas as classes"."

O filme singelamente utiliza a jornada mítica do herói para contar, nos dias de hoje, como um mito pode ser perpetuado a partir da martutenção das tradiçōes seculares de uma cultura. Burgoyne (2002) discute também a percepção de Victor Turner (já citada na epígrafe) do "refazer cultural" do cincma como uma possibilidade de reler o passado de modo a transformar determinadas verdades. A questão do uso da jornada do herói pode ser vista dentro dessa possibilidade a que se refere Burgoyne, utilizando a noção de "manifestação dupla" de Bakhtin. quando há uma adaptação de um gênero antigo a um novo contexto." Essa "manifestação dupla" indica que o filme Whale Rider pode parecer "reiterar posiçōes que 
são fundamentais para as formas mais tradicionais de nacionalismo" (BURGOYNE, 2002, 12), mas na verdade, - gênero funciona como expressão da memória cultural dos povos Maori, no caso do filme em tela.

Issovemcom todososimpassesqueocontemporâneo joga diante dos nossos olhos: o conservadorismo do avô (competentemente interpretado por Rawiri Paratene), que quer a todo custo manter a tradiçāo Maori, que é patriarcal (mas nem tanto); a família que pouco a pouco se modifica diante das situaçōes postas pelo contemporâneo, como, por exemplo, o fitho mais velho, Porourangi, que rompe com as tradições ao deslocar-se da Nova Zelândia para a Europa, onde vive de sua arte - o locus dos laços com a cultura Maori, ao esculpir pequenos totens e outros objetos. O pai conservador, no entanto, é incapaz de perceber na arte do filho esse elo, vendo-a apenas como "lembrancinhas". Porourangi, no momento dessa fala, havia acabado de dizer que estava refazendo sua vida na Alemanha e que Anna, sua companheira, estava grávida. Koro sentiu-se mais uma vez desrespeitado porque havia escolhido outra mulher para ofilho. É quando Porourangi diz: "Você nem sabe quem eu sou", e ele responde: "Sei quem você deveria ser", demarcando a diferença de expectativas entre pai e filho.

O rompimento de Porourangi com a sua cultura também aparece no seu casamento com Anna, uma alemá. Mas esse rompimento é apenas parcial porque a mitologia aproxima a loura europeia dos Maori, a partir da escolha do seu nome. Anna, segundo Robert Graves (1961, p. $369-70$ ), é aquela que pode ter muitos filhos; é também uma deusa-lua da fartura para os alemães, especialmente de Münster, norte da Alcmanha. O filme mostra Anпa grávida, o que torna a relação mítica bastante concreta e atesta que a escolha desse nome não foi em vāo. A estrangeira grávida de um/a filho/filha de um Maori traz também para essa cultura a sua própria, tornando possível a percepção de que essa nova criança hibridamente carrega dentro de si elementos de duas culturas tão diversas. mas que tornaram possivel o seu nascimento. 
7 Cf. artigo do Los Angeles Times, de $\mathrm{K}$. 'Turan, de 6/6/2003. para argumento semelhante.
Outro exemplo do descompasso entre a tradiçāo Maori e o contemporâneo está na figura do segundo filho, Rawiri, "gordo e feio", e deserdado da sorte por nāo poder ocupar o lugar do irmāo que, por herança ancestral, deveria ser o sucessor de Koro, mas que foi embora, quebrando a tradição. Rawiri representa os outros membros da comunidade marginalizados dentro da família, da cultura. Esse descompasso é percebido por Koro, o chefe Mạori, mas sua percepçāo é conservadora, e a necessidade de mudar essa realidade traduz-se também de forma conservadora. O que ele quer é a manutençāo da tradição dentro dos moldes patriarcais, sem alterar o rumo de absolutamente nada; sem permitir que os avanços sociais desloquem posturas conservadoras, abrindo, assim, espaço para mudanças. A forma que Koro encontra para isso é criar uma escola de tradiçōes para os filhos adolescentes primogênitos, para que estes nāo terminem como os pais que se evadiram da cultura Maori, como é o caso de Porourangi, ou como o pai de Hemi, o menino escolhido por Koro para sucedê-lo como chefe dos Whangara, que está mais interessado na cultura do alcool ou da droga?

O terceiro e mais importante descompasso vai se revelar a partir do nascimento da protagonista, que passo a discorrer a seguir.

\section{Whale Rider a via do contraste entre o velho e o novo}

O filme é marcado por cenas que se repetem para contrastar o novo e o velho, no sentido de mostrar que a diferença pode ser o elemento necessário para empreender mudanças.

A) O jogo nascimento/ renascimento e o mito de Paikea

As águas turvas que marcam o nascimento da protagonista no início do filme são retornadas no seu desfecho através do mar, para marcar o renascimento da menina como a líder de seu povo. Issas águas turvas 
trazen ao mundo um casal de gêmeos, mas o bebê do sexo masculino morre e leva a mãe junto. $O$ bebê do sexo feminino sobrevive, demarcando, assim, o seu caráter de resistencia, algo que aproxima a protagonista, logo de entrada, à herança do herói Paikea no presente da comunidade de Whangara.

Um site neozelandês consultado sobre mitologia Maori afirma que "Nas sociedades antigas da Polinésia, mitos sobre Paikea personificam a aterradora persistência das criaturas que desafiaram e sobreviveram aos mares bravios". A menina de fato aprende desde o nascimento a dor da perda e da rejeiçāo ("Nào houve alegria quando et nasci". conta a narradora-personagem numa voz-off). Aprende desde cedo a exorcizar a dor com a resistência que exibe ao longo do filme.

Quando Koro proibe o filho de usar o nome de "Paikea" para nomcar a menina, porque "nāo se pode destespeitar coisas sagradas", é possivel retomar o Porourangi, contudo, mantém a sua decisão. A menina carrega o nome ancestral de Paikea, mas, na verdade, seu nome passa a ser "Pai", uma redução pela metade do original. Vale aqui uma leitura feminista, no sentido de que essa diminuição não foi simplesmente motivada por um fator de carinho e intimidade. Pode-se ler aqui um reforço à minimização cultural do papel das mulheres na cultura Maori, que é o que passo a discutir na sequência. As lacunas existentes sobre a participação das mulheres na história dos Maori são atribuidas à censura do colonizador europeu, que filtrou as informaçóes que. segundo a sua ótica, eram relevantes para os seus propósitos de colonizaçào. "Outra razão é que nuitas dessas histórias foram registradas apenas pelos homens Maori e, assim sendo, passaram também pelo crivo de importância que esses davam às mulheres dentro de sua cultura. $E$ aqui nảo se pode dizer que elas foram "apagadas". mas essas histórias certamente teriam versōes diferentes. caso tivessem sido contadas por outra fonte. no caso, as próprias mulheres. Nessc particular, of filme de Niki Caro parece pertencel ao
${ }^{B}$ Disponjvel em chetp://folksong.org.nz/ paikeas Acesso em 27 de março de 2005.

- CE. Orbell (1992. p. 288-304). 
10) The Listencr, $25 / 1 / 2005$ que o critico Homi Bhabha chama de "narrativa nacional híbrida", que, na lejtura de Burgoyne (2002, p. 25), são narrativas construidas "a partir de histórias que têm sido excluidas dos relatos tradicionais", por serem "plurais e conflitantes" e por exigirem construçōes diferentes do passado nacional. A diretora de Whale Rider conseguiu realizar uma releitura da narrativa mítica dos Maori e incluir a percepção de gênero no contexto contemporâneo da comunidade Whangara, que também nào escapou da inclusão das mulheres na construção de sua história, seja ela arravés do mito ou da própria história factual.

Orbell fala que os homens Maori reconheciam a participação das mulheres na culcura, mas seu papel era inferior ao deles. Entretanto, mulheres socialmente bemnascidas na comunidade (possivelmente aquelas que descendiam de figuras míticas como Paikea, por exemplo), podiam expressar-se publicamente sobre assuntos de seu interesse. Além disso, outra informação relevante sobre o feminino na cultura Maori diz respeit to à liberdade sexual das mulheres. Isso tem relaçāo direta com o fato de que os homens Maori são Tapu, ou seja, sāo considerados sagrados, e as mulheres sāo Noa, ou profanas. Como as mulheres nāo tinham Tapu, podiam tomar a iniciativa no sexo, além de ter amantes antes do casamento. No filme, podemos ver isso quando a namorada de Rawirl (segundo filho de Koro e Nanny Flowers) se alvoroça toda com a chegada de Porourangi (primogênito que escapa da tradição) da Europa e o abraça sensualmente. A avó. brilhantemente protagonizada pcla atriz Vicki Haughton, diz cortantemente a ela: "Quantos dos meus filhos você precisa, garota?"

B) O herói desejado e a heroína real

A jornada do herói/heroína foi muito bem aproveitada no filme. Segundo uma das muitas criticas publicadas, "The Chosen One", de Philip Mathews, Whale Ricleré um filme que trata da trajetória mítica de um herói tal como Arthur, ou I.uke Skywalker: "o herói que näo sabe de si"."t $\mathrm{E}$ eu acrescentaria tantos outros. 
como o Neo de "Matrix I", entre os homens, se essa fosse uma trajetória apenas masculina."

A heroína de Whale Rider, no entanto, tem uma certa consciência de seu papel, o que a diferencia dos heróis homens. $O$ filme mostra isso de forma clara quando Pai insiste em ocupar seu lugar jurito ao avô. É claro que os reveses sāo muito marcados também, mas a diretora Niki Caro soube aproveitar o fato de seu filme ter uma heroína consciente e que, na adolescência, năo se encaixa simplesmente no despertar da sexualidade e sim da espiricualidade, conforme afima em entrevista a Lorena Muñoz, para o Times, em 6/5/2003. Esse dado é interessante até para mostrar que a jovem atriz adolescente Keisha Castle-Hughes, neozelandesa e que vive na comunidade Whangara, também sabia da importância de desempenhar um papel tão forte quanto - de Pai. Ela afirma, nа mesma entrevista, que "Toda menina cresce pensando que näo é boa o bastante para fazer isto ou aquilo, mas eu entendi que meninas poder fazer qualquer coisa". Fugindo do padrāo das super ${ }^{*}$ heroinas hollywoodianas, a protagonista de Whale Rider é urna heroína mais pé no chão, conforme escreve Muñoz. Concordo integralmente.

Com a morte do neto, Koro, chefe dos Whangara. fica destituído de um descendente do sexo masculino para levar adiante as tradições Maori, pois, segundo elas. o primeiro filho de cada chefe é descendente direto de Paikea, ${ }^{12}$ Resta-lhe a neta, mas a neta é do sexo feminino. a quem ele rejeita desde o inicio, ao dizer que a menina "nào tem importância para mim. Ela quebrou a linhagem de descendencia masculina", Assim, Koro representa os obstáculos para que o novo se estabeleça, mas pode-se dizer também que é por sua causa que tudo segue o seu curso, inclusive as transgressões.

Uma cena do filme que marca a passagem de tempo após o nascimento de Pai, o ir embora de Porourangi para a Europa e a educação dos avós para a menina, acontece quando o avô Koro retorna da escola trazendo a neta adolescente montada no cano da bicicleta. Há duas coisas
"Meu "Matrix" ou o mundo mítico revisitado" (2003, jnédjto) faz una leirura crítica dos filmes da série "Matrix", discutindo o uso que o fitne laz da jornada mítica do herói.

11 Cf. artigo de Hali no Sidney Monning Herald, de 10/5/2003, para una crltica a filme e que fala sobre a descendéncia entre os Maori. 
a observar aqui: a fisionomia andrógina de Pai, que marca de corta forma a indefinição adolescente quanto ao sexo (herói? heróna?), e a camisa usada por ela, que tern o número 27 estampado na frente e cuja soma é igual a 9, ou seja, o número que demarca o fim de um ciclo e o início de outro. Esses dados num filme que trata de mitos e lendas não são à toa. Também nāo é à toa o fato de Pai retornar da escola montada numa bicicleta com o avó.

O caminho simbólico nem sempre é fácil, mas, nesse caso, a passagem do mito para o real é quase literal: traz a questão da educação e do avô - descendente direto de Paikea - montado não numa balcia, mas numa máquina de transporte. $\mathrm{E}$ isso se configura mais adiante na história quando Pai começa o seu processo marginal de iniciaçāo - é expulsa da escola das tradiçōes, mas fica a espiar pela janela o que os meninos aprendem, ou seja, domar a raiva e o medo com o uso da Taiaha. Como Pai aprende pela margem - esta c a história das mulheres, o caminho da margem -, é o tio, o segundo filho, deserdado do amor paterno, "gordo e feio", mas ex-campeāo de Taiaha, que a ensina a lutar, recomendado pela avó, outra figura feminina que mercce um destaque muito especial, o que farei mais adiante. $\dot{E}$ nesse momento, a partir do seu treinamento, que vai para a escola de bicicleta e ultrapassa o ônibus escolar. Isso mostra que a heroína está seguindo a sua jornada de forma quase linear, só que pela margem. $\mathbf{E}$ ela vence Hemi, o escolhido do avô, na luta com a Taiaha, ainda que seja forçada a se desculpar por ter vencido, por ter quebrado "o tabu da escola", conforme ouve do avô.

Há heróis que recusam o chamado para trilhar a jornada. Porourangi foi um desses, conforme já pontuado. Tomou-se uma figura da diáspora. Para completar. Koro quer que o filho leve a neta embora, porque, na sua rigidez patriarcal, a menina "nāo serve" para ele. Pai ouve desconsolada a fala do avô ao seu pai e sai correndo para o mar, lugar que sempre busca nas suas anguistias e crises. É para lá que Porourangi se dirige e protege a filha numa cena comovente (repetida depois com a avó, quando Koro destrata a neta mais uma ve $\%$ ). Na conversa entre pai e 
filha fica claro o autoritarismo de Koro nas duas geraçōes: à pergunta de Pai "Por que [Koro] não gosta de mim?", Porourangi responde: "Koro precisa de um profeta. Não dá para ele decidir quem é essa pessoa. Eu nāo posso ser o que ele quer". Ao que a filha responde: "Nem eu". Koro ouviu do filho, em cena anterior, que ele (o pai) nāo sabia quem o filho era. Na cena entre Porourangi e Pai, ele a conforta dizendo: "Eu sei quem você deve ser", mostrando, assim, que sua geraçāo é capaz de compreender o novo e abrir as portas para cle. Pai aceita ir embora com Porourangi, mas desiste no meio do caminho, porque, ao passarem diante do mar, Pai ouve o chamado ancestral da baleia entende que seu lugar é ali. Assim, a menina volta para iniciar o aprendizado mítico.

C) O feminino ancestral e o contemporâneo: a representaçāo da avó

A avó de Pai, Nanny Flowers, é una mulher forte, resistente e transgressora. Sua forma de ser revela o diferencial quanto ao exercício da autoridade, quando comparada ao avô. No que ele tem de turrāo, o estereótipo do hornem patriarcal e conservador que pensa que o mundo gira em torno de si, ela tem de suavidade e doçura, num contraste que é comum na mitologia dos povos Maoni, cujo pensamento tribal compreendia o mundo a partir da lógica das dualidades e pares de opostos (ORBELL, 1992, p.298). O mundo perceptivel para os Maori era visto num binômio luz/treva, alto/baixo, cru/cozido. leste/oeste, direita/esquerda, vida/morte e Tapu/Noa. Claro está que os homens compunham o registro do positivo e as mulheres o do negativo dessa lógica.

Assimilando esse direcionamento da lógica Maori, podemos ver no avô e na avó, o dưăo e a șave, respectivamente, mas essa suavidade nẫo deverá ser pensada como polo negativo simplesmente. A avó tem tanta força, mais até do que o próprio avô, cuja autoridade é desconstruída ao longo de um filme que mostra, além disso, a necessidade do equilibrio de forças que a sociedade contemporânea pede. 
13 Esta pintura do escritor inglés ilustra a capa de meu livro A imaginaça do Ceminino segundo $D$. H. Lawrence (Edufal: 1999).

14 Cf. artigo no $\mathrm{New}$ Yotk THMes, de 6/6/2003. que fala sobre essa perspectiva trazida pelo findme.
A avó mostra essa força desde o começo, quando está entre suas amigas, na cozinha da casa, entre panelas e potes, sentadas ao redor da mesa, jogando cartas e fumando, numa cena que lembra uma pintura de D. H. Lawrence da década de $20 .{ }^{13}$ A pintura mostra três mulheres sentadas numa cozinha: uma datilografa, outra fuma c a terceira escreve. Do lado de fora, o autor inglês, sentado sob uma árvore, escreve. $O$ que essa cena do filme implica é o caráter de transgressão das mulheres num espaço interior, o doméstico, de sua jurisdição, espaço em que dominam. Porque, para a avó, se Koro "pensa que sabe tudo sobre ser chefe. Ele não é chefe coisa nenhuma. Eu sou a chefe". Ou quando, dentro da mesma cozinha, Nanny diz a ele que ali naquele espaço quem manda é cla, desautorizando mais uma vez sua voz de chefe.

Duas outras cenas contrastam o uso da autoridade: quando Koro usa a bengala para pedir respeito aos meninos na casa de tradições e quando Nanny Flowers apenas olha para os jovens na escola. Essa cena pode corresponder ao que diz Orbell diante da possibilidade que as mulheres Maori bem nascidas tinham de se expressar publicamente em situações que lhes diziam respeito. A cona do filme é a que mostra a cerimónia em que Pai recebe o prêmio da escola e fala sobre sua origem. Em determinado momento, dois jovens pretendem sair por considerar a cerimônia irrelevante. A avó nem fala na cena, apenas olha para os rapazes que voltam cabisbaixos aos scus assentos.

Mas a extensâo do poder da avó está muito mais no plano do afeto que ordena a vida de Pai do que na tentativa de manter uma tradiçăo porque esta precisa subsistir a qualquer custo. A avó quer sim que os costumes se mantenham, mas dentro de uma perspectiva que inclua o afeto, que se abra para o novo, e isso é algo que pode levar muito tempo. E preciso dar tempo ao tempo para que a vida possa ser construída." ${ }^{\prime \prime} \dot{E}$ com a experiência de uma velha sábia que cla ensina a neta a ter paciência diante das situaçōes difíceis.

Essa percep̧ão do afeto torna a figura da avó numa pessoa capaz de curar as feridas psiquicas infringidas pelo 
avô na neta, como quando este diz que ela quebrou o tabu da luta com a Taiaha, por exemplo, e a obriga a pedir desculpas aos meninos. A cena mostra Pai tomando banho de costas para a porta e a avó chegando e carinhosamente começando a lavar-lhe o corpo, as costas, lugar de imensa vulnerabilidade para as pessoas. Nossas costas nunca são vistas por nós, exceto se a olhamos através de um espelho, ou se outra pessoa nos fala delas. Por isso, sāo vulneráveis a pancadas e a ataques traiçoeiros. ${ }^{15}$ No caso do filme, e avô quem provoca tudo isso, a partir de sua atiode preconceituosa diante da possibilidade (e inevitabilidade) de a neta ocupar o espaço que deveria ser de um neto homem. A avó, ao acariciar a neta, mostra a necessidade de reconhecimento do outro e de se dar tempo ao tempo.

D) Desencontros e encontros: o talismā perdidoe a verdadeira lider maori

As águas que lavam a dor de Pai na banheira com o carinho da avó têm sua contrapartida quando o avô leva seus iniciados meninos de barco para o mar e lá pretende receber deles o retorno pelo seu empenho: seu talismā com o dente de baleia é jogado no mar e os meninos têm de ir buscá-lo, mas nenhum consegue e o avô volta frustrado para casa. A frustração de Koro é tal que ele expuisa Pai de casa, porque, para ele, ela é a única culpada por todas as coisas erradas que aconteceram na sua comusidade.

A cena final do filme contrapóe-se à cena da formatura e premiação de Pai na escola. Fla convida o avó que não chega. Na sua comovente fala, ela relata o seu orgulho de ser quem é, ao mesmo tempo que expressa a sua dor de nảo ser quem o avô queria que ela fosse. Pai chora e canta o seu lamento, a sua dor e o seu orguho de ser Maori. Oferece ao avô ausente a homenagem.

Essa cena é cortada várias vezes pela cena ent que $\mathrm{O}$ avô na praia vê as baleias encalhadas. E. aqui, ele se pergunta "De quem e a culpa?" Essa fala vem de for do romance Whale Rider. Niki Caro, diretora do filme e também sua roteirista, utilizou não apenas o romance de Witi thimaera na construção dessa fantástica cena das is Ver A, Bleakley em Earth's Embrace (1989), para unta discussāo acerça das coscas do ser bumano e a sua vulnerabilidade psiquica. 
baleias encalhadas. A fala vem do conto "Whale", que fala sobre uma baleia encalhada que vira comida de gaivota.

Se há algum "culpado", claro está que é o próprio avô, pela sua dificuldade de encontrar os caminhos da contemporaneidade e se permitir o contato. Esse caminho inclui, evidentemente, uma abertura para as mudanças que o mundo de hoje pede e isso significa que os papéis de homens e mulheres nāo podem mais ser estabelecidos de forma permanente e autoritária pela tradição patriarcal, seja ela a de Paikea ou qualquer outra que exija o apagamento das mulheres na construçāo da sociedade.

$O$ desfecho do filme se dá finalmente a partir da derrota do avô, da sua teimosia que leva às últimas consequências a sua necessidade de manter o poder. $A$ corda do trator que deveria salvar a baleia rompe-se, da mesma forma como rompeu a corda do motor do barco em cena anterior, quando Koro responde a Pai sobre a origem dos Maori de Whangara. Pai consegue fazer o motor funcionar, mas é repreeendida pelo avô. Na cena do mar com as baleias encalhadas é a mesma coisa: ele nảo deixa Pai se aproximar, muito menos tocar a baleia. Isso cla só faz quando todos jả cansados deixam a praia. Ela vai lá, sussurra no ouvido da baleia, sobe nela a partir de um parasita e monta no grande ancestral, tornando verdadeira a história lendária do herói de Hawaiki, que veio para Aotearoa montado na baleia. Pai salva a baleia de morrer encalhada e assim, simbolicamente, redireciona os rumos da comunidade para a contcmporaneidade. É quando a avó devolve ao avô o talismà resgatado por Pai. Nem nesse momento o velho rabugento permite-se entender que foi a neta quem o resgatou. Só o mar cujas águas levaran a neta ć que torna possivel essa compreensāo. É finalmente após essa difícil jornada que, no hospital, tal como começou o filme, o avô se entrega ao destino, no sentido grego da palavra, e pede perdào à "Sábia Lider", que é a neta.

Para finalizar, resta ainda pontuar que o mito de Paikea que "cavalga" a baleia para chegar na terra de Aotearoa, parece querer dizer o seguinte: primeiro, que o mito pode ter sido transformado na sua recontagem 
que, segundo consta (cf. Orbell), foi feita quase que exclusivamente por homens (pelos colonizadores e pelos homens Maori). Nessa recontagem, apagaram a percepçāo do mito como uma imagem arquetípica do útero. A baleia é, portanto, uma representaçāo do feminino.

Em segundo lugar, oato de cavalgaré culturalmente associado ao masculino na sociedade patriarcal. Assim, Paikea pode ter sido transformado numa figura masculina. Mas, segundo o mito, a baleia também pode ser Paikea. Logo, seu "cavaleiro" pode, na verdade, ser uma "amazona".

Em terceiro lugar, o mergulho da baleia com seu "cavaleiro" nas profundezas do mar implica o mergulho no inconsciente, com a permissão deste. No filme, leva ao renascimento da menina rejeitada ao nascer. Fecha, portanto, um ciclo mítico - nascer-morrer-renascer.

Por fim, a baleia encalhada pode remeter à chegada à terra neozelandesa. Sua carne pode servir para alimentar o povo: a transformação de um tipo a outro de vivência - do mar à terra, a natureza sempre alimenta. Pode também levar à surdez patriarcal para ouvir as mudanças temporais, como a inclusão das mulheres na história dos povos do mundo. $O$ filme reconstrói isso.

$O$ desfecho do filme retoma a tradiçāo do antigo e do novo juntos, quando Koro, o avô, representando o passado, e Pai, representando o futuro, cantam e ela leva no pescoço o amuleto com o dente de baleia que foi do avô. E ali repete o discurso da diferença: "Não sou profeta, mas sei que meu povo seguirá em frente".

A histónia narrada pelo filme parece repetir o ciclo mít ico arturiano que sempre volta ao seu começo, a partir da morte do herói, o que significa a continuidade do processo. Em Whale Rider o diferencial é que a jomada da heroina não é igual à do herói e ela permanece viva. Pai é ainda uma menina adolescente, com uma vida inteira pela frente, ou seja, a cultura Maori, da comunidade de Whangara, ainda tem muito chão para percorrer, para aprender.

Esse final coletivo traz elementos arquetipicos da jornada: a cena final do filme mostra que o barco 
${ }^{16}$ Para os neozelandeses, cada batco representa a histónia de una tribo. $\mathrm{CF}<\mathrm{htip}: /$ www.maatori. coms [consulta feita em $18 / 3 / 2005]$.

17 Cf. Artigo de Ruby Rich, no San Francisco Ba Guardian, 25/06. $1 \% / 72003$. que simboliza a vida de Pai está finalmente pronto e vai ao mar. ${ }^{16}$ Mulheres e homens camjnham juntos, ra tão sonhada e talvez tdealista caminhada da harmonia, que vai do humano à natureza, naquela perspectiva que a ecocrítica hoje vê como a única possivel para realinhar o planeta, a partir do retecimento das relaçōes entre o humano e o não-humano. A comunidade de Koro, feita de homens e mulheres, passa a ser uma comunidade harmonizada e híbrida e celebra c ıecomeço da vida e da tradição. Mostra a sua abertura ao novo, pois lá está Porourangi, que levou a cultura dos Maori para fora de lá, com a sua mulher estrangeira grávida. E essencial: mostra Pai ao lado avô no barco da familia. É o novo caminhando ao lado do velho; é a presença da mulher na costura contemporânea do mito de Paikea. Assim, Pai cumpre o seu destino, que é dar continuidade à tradiçào dos povos de Hawajki, mas com uma feição nova.

Talvez a cultura Maori não seja, afinal, tão conservadora assim, especialmente se considerarmos que a Nova Zelândia foi o primeiro país, antes mesmo que os chamados países civilizados o tivessem feito, que permitiu o voto feminino no mundo, em $1893^{17}$, inclusive às mulheres Maori. Assim, quem sabe possamos dizer com a avó Nanny Flowers, que o avô pensa que manda, mas quem sempre mandou foi ela. Devagar, suavemente. pelos entremeios da cultura, a mulher vai construindo sua participaçāo na cultura, nas relaçōes sociais, e cavalgando, encantadoramente, em baleias. 


\section{Referências}

BLEAKLEY, Allan. Earth's Embrace. Bath: Gateway Books, 1989.

BRANDÃO, Izabel. "Matrix ou o mundo mítico revisitado", Inédito, 2003.

BURGOYNE, Robert. A nação do filme. Brasilia; Ed. Da UNB, 2002. Trad. René Loncan.

CAMPBELL, Joseph. The Hero with a Thousand Faces.

London: Paladin Books, 1988.

FRASER, James. The Golden Bough. London: M Papermack, 1987.

GRAVES, Robert. The White Goddess. London: Faber Books, 1988.

NEUMANN, Erich. The Great Mother- an Analysis of the Archetype. London: Routledge, 1963.

ORBELL, Margaret. Maori Mythology. In LARRINGTON,

C. (ed.) The Woman's Companion to Mythology. London:

Pandora Press, 1997, p. 288-304.

\section{SITES DA INTERNET CONSULTADOS}

$<$ http:/www.iconmovies.co.uk/whalerider>[consulta feita em 19/3/2005].

<http:/www.whaleriderthemovie.co.nz> [consulta feita em 19/03/2005].

ahte:/www.onfilm.co.nz/reviews/whale\%20rider.htm [consulta feita em 19/3/2005].

\section{ARQUTVOS DE SITES DA NOVA ZELANDLA:}

ahtip://mazori.com/ > [consulta feita em 19/3/2005].

- http:/www.mft.govt.nzisupport. 'kpm/waiata.htm = [consulta feita em 18/3/2005]. 
<http:/www.teara.govt,nz> [consulta feita em 27/3/2005].

\section{CRITTCAS JORNALISTICAS NA WEB SOBRE O FILME "WHALE RDER"}

«http://epipoca.cidadeinternet.com.br [consulta feita em $19 / 3 / 2005]$.

Chttp:/divirta-se.correioweb.com.br/videos.htm?codigo=792s: Correio Braziliense Web Degustação, 23/3/2005.

Folha Online - Especial - 2003 - Mostra Br de Cinema/ Folhao 1.htm [consulta feita em 19/3/2005].

The Whale Rider - New Edition.

HALL, Sandra. Whale Rider. In Sydney Morning Herald. $10 / 5 / 2003$ [18/3/2005].

MATHEWS Phili The Chosen One. In The Listener 25/1/2003 $[18 / 3 / 2005]$.

MITCHELL, Elvis. A Girl Born to Lead, Fighting the Odds. In New York Times, 6/6/2003.

MUÑOZ, Lorenza, A Girl Shall Lead Them. In: Los Angeles Tìnes, 6 de maio de 2003 [18/3/2005].

RICH, Ruby. Finding Niki. In: San Francisco Ba Guardian, 25/6-1"1/7/2003.

TRAVERS, Peter. Whale Rider. In: Rolling Stone. 30/5/2003 [18/3/2005].

TURAN, Kenneth. Whale Rider. In: Los Angeles Times, 6 de junho de 2003. 